\title{
What Do Women Really Want? Lessons for Breastfeeding Promotion and Education
}

\author{
Amy Brown
}

\begin{abstract}
Background: Promoting breastfeeding is a strategic priority, but breastfeeding rates remain low in the United Kingdom. Women value breastfeeding promotion and education, but a different strategy may be needed to continue to raise breastfeeding rates. New mothers, as the experts, are best placed to inform these changes. The current study explored new mothers' attitudes toward breastfeeding education and promotion, evaluating experiences and examining ideas for change.

Materials and Methods: One thousand one hundred thirty mothers with a baby aged 0-2 years old who had planned to breastfeed at birth completed a questionnaire consisting of both closed and open-ended questions exploring their attitudes to breastfeeding promotion and support.

Results: Overall, the findings showed that mothers valued breastfeeding information, but believed that changes needed to be made to current messages. Key themes included a move away from the perception that breastfeeding is best (rather than normal), emphasis on wider values other than the health benefits of breastfeeding, and a message that every feed, rather than just 6 months exclusive breastfeeding, matters. Mothers also highlighted the need for promotion and education to target family members and wider society rather than simply mothers themselves, all of whom influenced both directly or indirectly maternal decision and ability to breastfeed. Mothers suggested ideas for promotional campaigns or how specific groups or methods could be used to increase support, including education for children, TV adverts, and using established online sources of breastfeeding information. Conclusions: The findings are important both for those supporting new mothers to breastfeed and those involved in breastfeeding policy and promotional messages.
\end{abstract}

\section{Introduction}

$\mathbf{T}$ HE IMPORTANCE OF BREASTFEEDING FOR INFANT and maternal health is well established, ${ }^{1,2}$ with breastfeeding recognized as a key strategy to improve population health and reduce inequalities. ${ }^{3}$ Promoting breastfeeding is therefore an important strategy for optimal infant and maternal health. ${ }^{4}$ In the United Kingdom, schemes such as the NHS "Start for Life" encourage new mothers to breastfeed, emphasizing the importance of breastfeeding for both mother and baby. Alongside this, the Baby Friendly Initiative strives to encourage new mothers to breastfeed through the provision of education antenatally, promoting hospital practices that encourage mothers and infants to stay close together and removing any unnecessary use or promotion of baby milk substitutes. A large part of this is training staff to provide informed, accurate, and consistent advice and support both antenatally and in the postnatal period. ${ }^{5}$
Knowledge that breastfeeding is the optimal nutrition for an infant is well understood, even among women who choose to formula feed from birth. ${ }^{6}$ Intention to breastfeed is strong and many women want to receive information regarding breastfeeding. ${ }^{7}$ However, despite this, levels of breastfeeding are low in the United Kingdom. Although rates are slowly increasing, with $81 \%$ of mothers now initiating breastfeeding at birth, ${ }^{8}$ only $34 \%$ of mothers are breastfeeding at all at 6 months with less than $2 \%$ doing so exclusively for this period. ${ }^{9}$ This is not simply intention to stop; up to $80 \%$ of mothers who stop breastfeeding before 6 weeks report that they do so before they are ready. ${ }^{9}$

We know that reasons behind formula use are complex, involving many biological, psychological, and social factors. ${ }^{10-12}$ However, given our understanding of breastfeeding issues and the government's strategic priority to promote breastfeeding, yet consistently low rates of breastfeeding continuation,

Department of Public Health, Policy and Social Sciences, Swansea University, Swansea, United Kingdom.

(C) Amy Brown 2016; Published by Mary Ann Liebert, Inc. This is an Open Access article distributed under the terms of the Creative Commons Attribution License, which permits unrestricted use, distribution, and reproduction in any medium, provided the original work is properly cited. Mary Ann Liebert, Inc. offers reprint services for those who want to order professionally produced copies of articles published under the Creative Commons Attribution (CC BY) license. To obtain a price quote, email Reprints@liebertpub.com. Please include the article's title or DOI, quantity, and delivery destination in your email. 
potentially a different, more intensive, or more effective way of tackling low breastfeeding rates is needed. ${ }^{13,14}$

One critical element is providing new mothers with high quality accessible support after they have given birth. However, engagement during pregnancy is also important. Mothers who feel prepared, knowledgeable, and confident about breastfeeding typically have better outcomes after birth, ${ }^{15-17}$ and enabling women to breastfeed by providing high quality, widespread practical and informed education and support is central to improving breastfeeding rates. ${ }^{18}$ However, specifically how this information and support is publicized may need a different direction.

Two main challenges for breastfeeding education and promotion arise. First, if the majority of women understand the benefits of breastfeeding and want to breastfeed, what should breastfeeding promotion and education cover? Second, how can breastfeeding promotion and education help to break down wider barriers to enable women to breastfeed? Importantly, any messages promoted must be relevant to mothers today and placed within an appropriate wider social and cultural context. ${ }^{19}$ The aim of the current study was to examine directly what information new mothers feel they need in relation to breastfeeding promotion and education, what strategies they believe worked, and what practices they felt were restrictive.

\section{Materials and Method}

\section{Design}

A retrospective mixed methods study, exploring mothers' perceptions of breastfeeding education and promotion messages.

\section{Participants}

Ethical approval was granted by a Department of Psychology Research Ethics Committee. All aspects of this study were performed in accordance with the ethical standards set out in the 1964 Declaration of Helsinki. Participants included mothers with a baby aged up to 2 years who had planned during pregnancy to breastfeed. A 2-year limit was chosen in line with World Health Organization recommendations to breastfeed for the first 2 years postpartum and beyond. ${ }^{20}$ The decision was made to exclude mothers who intended to formula feed as they would likely have consistently different views toward the need for breastfeeding support.
Participants were recruited from local mother and baby groups and through online parenting forums based in the United Kingdom. Paper copies of the questionnaire were distributed through local groups. For online participants, advertisements were placed on parenting forums and participants used an online link to complete the questionnaire using SurveyMonkey. Participants from the face-to-face groups were also given an online link to complete the questionnaire if required, and likewise, online participants could request a paper copy. Both the paper and online version of the questionnaire contained an information and consent section and debrief information. Details of how to contact the researcher for further information were included. All participants were required to give first three letters of UK postcode to confirm they were UK based.

\section{Measures}

Participants completed a questionnaire consisting of openended questions examining their beliefs regarding breastfeeding education and promotion in the United Kingdom (Table 1). Questions examined experiences of breastfeeding education and promotion in conjunction with exploring how participants believed breastfeeding should be promoted. Participants were prompted to give examples of both what worked and what did not. Alongside this, participants responded to a series of statements examining breastfeeding promotion using a fivepoint likert scale [strongly agree to strongly disagree].

Participants provided age, education, and marital status alongside details regarding occupation, which were coded according to the National Statistics Socio-Economic Classification self-coded method. ${ }^{21}$ Participants also indicated whether they had planned to breastfeed, how they fed at birth, and breastfeeding duration if they had stopped breastfeeding.

\section{Data analysis}

Quantitative data were analyzed using SPSS version 20. The proportion of respondents agreeing with each statement was calculated by combining those who agreed or strongly agreed with each statement.

Qualitative data were analyzed using a simple qualitative descriptive approach. ${ }^{22}$ A content analysis was performed for each script. This entailed reading through each script to identify emerging themes. Themes were grouped into key themes and subcategories. The aim was to explore scripts following principles of data saturation with analysis continuing until it was felt

\section{Table 1. Open-Ended Questionnaire Items}

1. Did you receive any information about breastfeeding during pregnancy or after your baby was born? What and from where? Was this information useful?

2. What information about breastfeeding would you like to have received during pregnancy and after your baby was born?

3. What do you think overall about breastfeeding education and promotion messages in the UK?

4. How did information about breastfeeding and breastfeeding promotion make you feel?

5. Do you think breastfeeding education and promotion actually affects breastfeeding rates? How? What impact does it have?

6. Can you think of any positive examples or messages of breastfeeding education and promotion you have seen? Why were they positive?

7. Can you think of any negative examples or messages of breastfeeding education and promotion you have seen? Why were they negative?

8. What do you think about the often used "breast is best" message?

9. Do you have any ideas for how breastfeeding should be promoted? What messages or information would you like to see emphasized and how?

10. Do you think enough is done to educate new parents and promote breastfeeding in the UK?

11. Who should breastfeeding promotion be targeted at? 
that no new themes or ideas were emerging. A random sample of scripts was selected for confirmation of themes by two independent coders. Agreement was found in over $90 \%$ of cases.

Given the significant sample size, a decision was made to analyze all quantitative responses, but to select 200 responses for qualitative analysis. This sample was stratified to reflect numbers who breast or formula fed at birth, for those still breastfeeding or not, and ensuring this sample reflected the original spread of maternal age, education, and parity. Participants were randomly selected from those groups. This number clearly exceeded recommended minimums for qualitative data, ${ }^{23,24}$ and saturation of main themes was found within expected numbers. ${ }^{25}$ However, it also allowed for a quantitative description of occurrence of themes. The proportion of participants who agreed with each key and subtheme was recorded in a table to allow an additional descriptive quantitative analysis of data

\section{Results}

\section{Quantitative results (entire sample)}

For the full sample, 1130 mothers with a baby aged 0-2 years had full quantitative data. Maternal mean age was 30.62 (SD: 4.32), with mean years in education of 13.23 (SD: 3.34). For full demographic details see Table 2. Mean age of infant was 39 weeks (SD: 38.2). Thousand and four (88.8\%) breastfed at birth, while $126(11.2 \%)$ formula fed at birth, despite intention to breastfeed. Mothers $(45.2 \%)$ were breastfeeding at the time of the questionnaire (31.04\% exclusively, $14.2 \%$ partially). Those (92.4\%) who stopped within the first 6 weeks stated that they would have liked to breastfeed for longer.

Examining quantitative responses, $89.1 \%$ believed that it was important to promote breastfeeding to pregnant mothers and $75.8 \%$ felt that breastfeeding promotion affected mother's decision to breastfeed. However, only $14.6 \%$ of mothers agreed that methods of breastfeeding promotion and education

Table 2. Participant Demographic Background

\begin{tabular}{|c|c|c|c|c|c|}
\hline \multirow[b]{2}{*}{ Indicator } & \multirow[b]{2}{*}{ Group } & \multicolumn{2}{|c|}{$\begin{array}{c}\text { Full } \\
\text { sample }\end{array}$} & \multicolumn{2}{|c|}{$\begin{array}{l}\text { Stratified } \\
\text { sample }\end{array}$} \\
\hline & & $\mathrm{N}$ & $\%$ & $\mathrm{~N}$ & $\%$ \\
\hline \multirow[t]{6}{*}{ Age in years } & $\leq 19$ & 22 & 1.9 & 4 & 2.0 \\
\hline & $20-24$ & 184 & 16.2 & 30 & 15.0 \\
\hline & $25-29$ & 315 & 27.8 & 54 & 27.0 \\
\hline & $30-34$ & 411 & 36.4 & 75 & 37.5 \\
\hline & $35 \geq$ & 198 & 17.5 & 37 & 18.5 \\
\hline & School & 187 & 16.5 & 30 & 15.0 \\
\hline \multirow[t]{3}{*}{ Education } & College & 301 & 26.6 & 50 & 25.5 \\
\hline & Higher & 404 & 35.7 & 74 & 37.0 \\
\hline & Postgraduate & 238 & 21.1 & 46 & 23.0 \\
\hline \multirow[t]{4}{*}{ Marital status } & Married & 801 & 70.8 & 144 & 72.0 \\
\hline & Cohabiting & 222 & 19.6 & 38 & 19.0 \\
\hline & Partner & 35 & 3.1 & 11 & 5.5 \\
\hline & Single & 69 & 6.1 & 7 & 3.5 \\
\hline \multirow[t]{4}{*}{$\begin{array}{l}\text { Maternal } \\
\text { occupation }\end{array}$} & $\begin{array}{l}\text { Professional/ } \\
\text { managerial }\end{array}$ & 402 & 35.5 & 82 & 41.0 \\
\hline & Skilled & 307 & 27.2 & 50 & 25.0 \\
\hline & Unskilled & 145 & 12.8 & 20 & 10.0 \\
\hline & $\begin{array}{l}\text { Stay-at-home } \\
\text { mother }\end{array}$ & 276 & 21.2 & 48 & 24.0 \\
\hline
\end{tabular}

are currently excellent, and $17.9 \%$ of mothers were happy with the information they received from health professionals during pregnancy. Overall, only $8.2 \%$ believed that the "breast is best" slogan was a good way to increase breastfeeding rates. Specifically, although $94.8 \%$ of participants felt that breastfeeding promotion tackled the health benefits of breastfeeding, only $48.4 \%$ felt that they had been given sufficient information on how to find support after the birth, with $10.4 \%$ believing that breastfeeding promotion messages prepared mothers for what it would be like to breastfeed a baby.

\section{Qualitative results (stratified sample)}

The qualitative responses of 200 mothers were therefore included in the qualitative analysis. The sample was stratified closely for percentage breastfed at birth $[n=178(89 \%)-$ compared to $88.8 \%$ in the full sample) and still breastfeeding at time of questionnaire $[n=90(45 \%$ - compared to $45.2 \%$ in the full sample). This stratified sample was then matched as closely as possible for maternal age, education, and parity, although naturally this was not an exact match but of close similarity [see Table 2]. The mean age in the stratified sample was $30.66 \%$ (SD: 4.29), with a mean number of years in education of 13.28 (SD: 3.31).

In a series of open-ended responses, mothers critiqued their experiences of breastfeeding promotion and education, giving suggestions for what information and guidance they would have liked to have received or felt would work better. Frequency of main and subthemes can be found in Table 3. Overall, as shown in the quantitative data, mothers were strongly in favor of breastfeeding being promoted and pregnant women receiving breastfeeding education during pregnancy.

"We definitely need to be telling new mothers about why breastfeeding is so good. It is important that they learn about the differences between breast and formula and make an informed choice. I think this should play a larger role in antenatal education but also be extended to everyone else. Everyone needs to know why breastfeeding is so important for mums to stand a chance of making this work"

However, mothers went on critique the specific information they had received, examining both positive and negative examples they had encountered.

Breast is not best; it is the normal way to feed an infant. The strongest idea reflected throughout the data focused upon the semantics of how breastfeeding promotion and education should be delivered. Breastfeeding should not be portrayed as "best," but as normal. Breastfeeding, as the biological norm, should be perceived as the automatic behavior rather than an active choice being made. Participants believed that by labeling breastfeeding as "best", the subcontext was that formula feeding was perfectly good enough. It also portrayed breastfeeding as something complicated that had to be worked toward, with the expectation that not many would manage this.

"Breast is best but this puts breastfeeding on an unobtainable pedestal for some people. This then makes infant formula seem to be reachable, normal and something that has all the stuff needed for babies. Instead breastfeeding should be marketed as normal and perfect."

"Breast milk does not reduce the chances of a child being obese etc, formula increases the chance of them being obese. We may be sparing some feelings by flipping reality on its head but in the long run we are only hurting ourselves.", 
Table 3. Themes, Subthemes, and Frequency of Agreement $(N=200)$

\begin{tabular}{|c|c|c|c|}
\hline Theme & Subtheme & $\mathrm{N}$ & $\%$ \\
\hline $\begin{array}{l}\text { 1. Breast is not best; it is the } \\
\text { normal way to feed an infant }\end{array}$ & $\begin{array}{l}\text { Breastfeeding as the biological norm } \\
\text { Creation of a two-tier system where formula milk is good enough } \\
\text { Suggestion that breastfeeding is out of reach for some } \\
\text { Importance of discussing benefits outside of health }\end{array}$ & $\begin{array}{l}154 \\
121 \\
105 \\
141\end{array}$ & $\begin{array}{l}77 \\
60.5 \\
52.5 \\
70.5\end{array}$ \\
\hline $\begin{array}{l}\text { 2. Do not focus solely on the } \\
\text { health impact of breastfeeding }\end{array}$ & $\begin{array}{l}\text { Removing assurance that breastfeeding will stop all illness } \\
\text { Not focusing on idea of breast milk as a health product } \\
\text { Do not need to be told the benefits } \\
\text { Leads to clash between formula and breastfeeding mothers }\end{array}$ & $\begin{array}{r}103 \\
42 \\
136 \\
75\end{array}$ & $\begin{array}{l}51.5 \\
21 \\
68 \\
37.5\end{array}$ \\
\hline $\begin{array}{l}\text { 3. Take it a day at a time-every } \\
\text { feed makes a difference }\end{array}$ & $\begin{array}{l}\text { Stop breastfeeding if cant do so exclusively } \\
\text { Every drop matters } \\
\text { Needs to fit within women's lives }\end{array}$ & $\begin{array}{l}112 \\
104 \\
152\end{array}$ & $\begin{array}{l}56 \\
52 \\
76\end{array}$ \\
\hline $\begin{array}{l}\text { 4. Tell us the truth-it can be } \\
\text { challenging }\end{array}$ & $\begin{array}{l}\text { Need realistic information about what breastfeeding is like } \\
\text { Felt unprepared for what it was like } \\
\text { Felt doing it wrong after the birth } \\
\text { Felt disillusioned and misled } \\
\text { Need information on how to deal with difficulties } \\
\text { Experiences from other mothers } \\
\text { Non-NHS sources of advice as gold standard } \\
\text { Educate fathers } \\
\text { Educate family } \\
\text { Educate society }\end{array}$ & $\begin{array}{r}168 \\
157 \\
111 \\
86 \\
134 \\
111 \\
148 \\
166 \\
153 \\
146\end{array}$ & $\begin{array}{l}84 \\
78.5 \\
55.5 \\
43 \\
67 \\
55.5 \\
74 \\
83 \\
76.5 \\
73\end{array}$ \\
\hline 5. Target a wider audience & $\begin{array}{l}\text { Educate the public as to the importance and need } \\
\text { Make breastfeeding more visible in society } \\
\text { Highlight the legal protection that exists } \\
\text { Advertise breastfeeding on TV/billboards/magazines } \\
\text { Use celebrities } \\
\text { Educate children and young people }\end{array}$ & $\begin{array}{r}104 \\
110 \\
52 \\
85 \\
68 \\
154\end{array}$ & $\begin{array}{l}52 \\
55 \\
26 \\
42.5 \\
34 \\
77\end{array}$ \\
\hline
\end{tabular}

Do not focus solely on the health impact of breastfeeding. Many mothers reported how they had received plentiful information on the health impact of breastfeeding, but less emphasis was placed on other reasons that might encourage mothers to breastfeed. Mothers highlighted how they felt stronger precedence should be placed on more immediate tangible hooks for the mother; factors such as convenience, lower cost, ease, and closeness, alongside factors such as emotional closeness and instinct.

"Breastfeeding is about so much more than health. It is about cuddles, and closeness and bonding. It saves time, costs nothing and you can never forget to take it out with you. Why don't we emphasise these things more?"

Moreover, mothers raised the idea that by focusing on simply the health benefits of breastfeeding, there was the risk that breast milk appeared to conceptualize almost as a product that the baby must have for its health, rather than simply being the normal way to feed a baby.

"Breastmilk is not a medication, supplement or product and sometimes it is promoted as this thing your baby must have. It's not about that. It's so much more."

Related to this was the misinterpretation that selling breastfeeding as simply promoting health was often misinterpreted as an assurance that a breastfed infant would never become ill. Mothers recalled how they were often surprised or disappointed when their breastfed infant did get ill.

"Although there are health differences between breast and formula fed babies they are not guarantees. Breastfed babies can still get ill so if mothers are sold the idea of breastfeeding on health benefits alone and then their baby gets sick it can make them feel like they did it wrong or that it wasn't actually that good and they might as well formula feed as their friend who did have really healthy kids".

Mothers noted that with the current emphasis on the health benefits of breastfeeding, combined with the concept of breast being "best," mothers felt they attracted quick criticism from those who did formula feed when their breastfed infant did fall ill. Their infant's illness was taken as "proof", that the messages about breastfeeding were wrong.

"There is a lot of defensiveness amongst some mothers who do not breastfeed at the idea of breastfed babies being healthier. I had a number of people pointedly notice that my breastfed baby had a cold/bit of dry skin/sticky eye saying that they thought breastfeeding was meant to stop all that and their formula fed baby didn't have it'.

Take it a day at a time-every feed counts. The World Health Organization ${ }^{20}$ recommends exclusive breastfeeding for the first 6 months, alongside continued breastfeeding up to the second year and beyond. However, a strong belief was that the way in which this information had been interpreted and disseminated often discouraged women from breastfeeding at all as they felt that if they did not follow these "rules" there was little point in continuing. Although mothers understood concepts of milk supply and the potential damage of supplementation, many felt overwhelmed by the thought of 6 months of exclusive feeding, or felt that any perceived benefit would only come from exclusive feeding.

"If you really want to boost breastfeeding, you have to abandon this black or white stance... It's a spectrum, with exclusive breast at one end, and exclusive formula at the other. But it's promoted as a black or white choice and most 
mums end up failing to keep all the rules and giving up the whole thing",

"It is overwhelming as a first time mum who is perhaps exhausted by the birth that she must now feed this baby exclusively for the next six months... You might have a mum who baulks at the idea of six months, but six weeks or even 6 days seems achievable for her. That is better than not at all."

This included recognizing that even when new mothers understood the guidance and wanted to follow it, breastfeeding had to fit within their wider experience. However, many felt that unless they breastfed exclusively they were judged for their choices.

"Please recognise that us mums are only human. We would love to focus only on our babies we really would. But sometimes our other children need attention, we need to go back to work or sometimes we have the audacity of putting our mental health first. Sometimes that means giving an occasional bottle of formula or stopping at four months old. Stop making us feel like we have failed when we have actually done a damn good job!'”

If discussions could be more open with women, giving them the information and tools they need to make an informed choice, perhaps women may breastfeed for longer, or even initiate when they otherwise would not, just for a few days. Importantly, recognition of what they have done, rather than what they have not, may help reduce feelings of guilt at stopping breastfeeding.

Tell us the truth-it can be challenging. A theme running throughout the responses was that women often felt ill prepared for what breastfeeding would truly be like. Antenatal preparation stressed only positive aspects of breastfeeding, presenting feeding as a simple and straightforward experience. However, many mothers felt that they encountered challenges, difficulties, or simply found that breastfeeding was not as they expected. Few mothers felt that they were prepared for the realities of breastfeeding and held high expectations of how simple it would be. When these were shattered, they became disillusioned or felt that they needed to stop breastfeeding as they must be doing something wrong, or that their baby was "difficult." Conversely, although they did not believe that breastfeeding should be labeled difficult, they felt that if they had been prepared for the realities of breastfeeding (the rewarding, the mundane, and the challenging), they felt they may have continued for longer.

"It was all so positive. Breast is best for your baby. Breastfeeding will help you lose weight. Breastfeeding will make bonding with your baby easier. Breastfeeding is a wonderful experience. Perhaps all that is true but it is in no way the whole picture. When I then found it difficult, at times demanding and my baby appeared to want to scream rather than snuggle serenely at my breast I felt like a complete failure and embarrassed and guilty that I felt that way to boot. If I'd known the truth I could have worked through all of this rather than thinking it wrong",

"Honest real information about how hard it can be to latch on, things you can do to help latch, most common issues and solutions to those. How it can hurt, its normal to struggle at the start, information about growth spurts, more information on how milk production actually works so mums can then make informed decisions on feeding and know if they do something like top up with formula then how it will impact their supply"
Considering what information new mothers needed, frequently, non-NHS sources were brought up, including online breastfeeding resources, blogs, and breastfeeding books. These books and websites in particular were seen as excellent examples as they provided detailed information, not simply about health benefits and latch but they had detailed information and suggestions of how to solve problems that might arise. These sources of information have been built up over time, are accurate, and widely seen to be excellent sources of information. One suggestion could be that the NHS openly directs women to these sites, both as a source of information and support, compiling a list of resources for them, rather than trying to recreate information on a smaller level.

"Dispelling BF Myths and Analytical Armadillo (and I am sure other blogs) are excellent, and I find them to be much more informative and supportive than some of the leaflets available.",

Importantly, mothers wanted information not only regarding the difficulties they might experience but how they could overcome these. Positive stories were recalled as to hearing realistic tales of breastfeeding from experienced friends or breastfeeding peer supporters during pregnancy, which helped them form realistic ideas about what breastfeeding would be like. This information was also invaluable to learning how although these difficulties might arise, they could be overcome.

"I went to this great class. We covered why breastfeeding is so important and how to do it but also what it was really like to breastfeed. Some local peer supporters came in and fed in front of us (which was the first time I had seen a baby breastfeed) and talked about problems they had and importantly how they got over them. They then gave us details of how to contact them and groups to go to once the baby was here. We felt part of something and like we knew what to expect."

Target a wider audience. Finally, mothers expressed a clear view that breastfeeding promotion had to encompass a much wider audience. Encouraging the support of breastfeeding from partners, family, and wider society was seen as a key step to ensuring that mothers received the encouragement and support needed to successfully establish breastfeeding. Mothers felt that if those around them were informed and knowledgeable about breastfeeding and recognized their role in supporting the mother, their job of breastfeeding would become easier.

"You can tell women that breast is best til the cows come home. But if their partner believes differently and the mother in law is trying to give the baby a bottle, who do you think is going to win? Tell mums by all means but also tell their wider familyget the message out there in a way everyone will buy into it"

Moreover, it was felt important to target society as a whole, so that new mothers would feel confident in their decision to breastfeed. If others understood the importance of breastfeeding, then new mothers would find it less challenging to feed.

"I know why breastfeeding is important. My partner knows why breastfeeding is important. But it's very difficult to put up with others' ignorant views. Educate the general public and it would be a lot easier. Even if this just means more awareness that you're not allowed to tell a woman to stop!"

Mothers also felt that if talking about, and seeing, breastfeeding became commonplace, then breastfeeding would 
become normalized in society. If society was encouraged to accept breastfeeding, then breastfeeding would become more commonplace, visible, and expected. Mothers felt that breastfeeding images needed to infiltrate every public space so that breastfeeding no longer became something that was viewed as different. Ideas for targeting wider groups and increasing acceptance billboard campaigns, having breastfeeding interwoven into television programmes, and just more promotional posters and breastfeeding welcome stickers.

"The only thing you can do is make it more normal and accepted. If everyone grows up seeing pictures of it, seeing women doing it, seeing it on soaps etc and seeing people doing it, it will be a normal natural thing to do."

Specifically, educating children and young people so that subsequent generations were informed and supportive as to the need of breastfeeding arose numerous times.

"Go into schools. Talk to the children before someone else gives them the idea that breastfeeding is something to be ashamed about and formula milk is normal."

Related to this, a common idea was that more should be done to actively promote breastfeeding to the general public through advertising campaigns in the same way that the formula companies do.

"Australia does some good adverts on TV which are very widely seen and help to counter formula promotion. PLEASE stop the TV ads for formula as they're so misleading and PLEASE promote breastfeeding on TV.",

"Formula companies advertise by showing bouncy, happy babies rather than just them sucking on a bottle. Maybe we need to see how we can promote breastfeeding in other ways than the more traditional.",

Utilizing celebrities as a means of promoting and "getting behind" breastfeeding was a suggestion that frequently arose. Mothers felt that when a celebrity endorsed or even simply mentioned that they were breastfeeding, it created an aspiration for others who supported that celebrity. It also meant that breastfeeding became talked about in newspapers, magazines, and on television and social media.

"Angelina Jolie BF twins for 3 months, Danni Minogue BF before shows on X Factor. Use strong role models like this to show those who won't try that it is not that difficult."

Mothers recognized that although new mothers are primarily responsible for breastfeeding, without a network which encourages, supports, and recognizes the importance of breastfeeding, their journey was going to be much more difficult. An approach that considers and targets the wider influences on the mother is needed. One mother summed this up:

"You have the ideal behaviour, the gold standard that we should be aiming for. But we have to realise that not everyone can do that. Yes we want it (they want it) but we want them to do lots of other things like not smoke or drink too much. Realise that just feeding for a few days is an achievement for some, or some will want to give formula too. Understand some mothers need to go back to work. Support, understand, enable. Nagging never works. Make breastfeeding seem non threatening, non embarrassing and normal and by taking a step back we might actually just get where we want to be."

Considering the findings as a whole, participants provided a wealth of information and ideas about their thoughts and experiences regarding breastfeeding education and promotion. Mothers highlighted how they believed that breast- feeding should be promoted as the normal biological way to feed an infant, highlighting factors outside of health and considering realistic experiences of breastfeeding. Promotion of the importance of breastfeeding needed to go outside of the mother, targeting those who support her and the wider views of society if breastfeeding was going to become the normal and expected behavior.

\section{Discussion}

This article presents the experiences, attitudes, and perceptions of a large sample of new mothers toward breastfeeding promotion and education in the United Kingdom. It highlights beliefs about what they feel works (and does not work) in relation to supporting and educating new mothers to breastfeed with suggestions to the information, guidance, and assistance mothers would like to receive. Overall, mothers felt that a new wider approach was needed as they perceived that people had become immune to current messages. In essence, mothers aspired for breastfeeding to become the cultural and social norm in the United Kingdom with the right support networks to inspire, guide, and enable women to breastfeed.

Considering the themes that emerged, there was a strong awareness that breastfeeding promotion had to operate within the social and cultural environment of new mothers, as highlighted by Dykes \& Flacking. ${ }^{19}$ The first of these messages considered that breastfeeding should not be portrayed as "best," but as normal. Breastfeeding, as the biological norm, should be perceived as the automatic behavior rather than an active choice being made. Typically, in other areas of health promotion, comparisons are made toward the biological norm. Messages surrounding smoking cessation are not phrased toward the benefits of not smoking, instead they highlight the risks to health of deviating from the biological norm. In breastfeeding promotion, however, breastfeeding is often considered to decrease risk of illness (rather than artificial feeding increasing risk), creating ideas of perfection rather than need. ${ }^{26}$ Indeed even the World Health Organization has a statement that "Exclusive breastfeeding for 6 months is best for babies everywhere",27 and the NHS a breastfeeding campaign entitled "Off to the best start.", 28 This may dilute health messages.

This wording may appear insignificant, but affects the way in which breast and formula milk are framed. For example, Hannan, Benton-Davies, \& Grummer-Strawn found that while agreement was high with the statement that "breastfeeding is healthier for babies," the majority disagreed with the statement that "Feeding a baby formula instead of breast milk increases the chances the baby will get sick." ${ }^{29}$ Rephrasing messages to highlight breastfeeding as the biological norm would both emphasize the potentially impact of formula feeding and also help reinstate breastfeeding as the normal option.

Second, mothers suggested that promotion should not focus solely on the health impact of breastfeeding. This sentiment echoes work by Burns et al. (2012) who described how breast milk is sometimes lifted to such a pedestal that emphasis becomes focused on the baby receiving the milk for its health, rather than the wider experience of breastfeeding, including that of the role of the mother in this "transfer." 30 Breastfeeding is not just about health; mothers breastfeed for a wide range of reasons, including emotional well-being, 
convenience, or just because it is natural, instinctive, or they want to, but this is rarely considered when discussing breastfeeding with new mothers, instead focusing on urging them to transfer the health benefits to their infant. Repositioning the arguments for breastfeeding away from purely health reasons was also suggested as one way of absolving some of the tensions between breast and formula feeding mothers and reducing reported feelings of guilt among mothers who cannot breastfeed, as it moves away from just being this required health intervention for their infant that they are "failing" to provide. ${ }^{31}$

A related idea was that the focus should be shifted away from an almost all or nothing approach to breastfeeding and recognize that every feed makes a difference. Although formula milk supplementation can reduce milk supply, ${ }^{32}$ exclusive formula feeding carries greater risk than partial breastfeeding, meaning that every feed does matter. ${ }^{33} \mathrm{Wo}_{\mathrm{o}}$ men should know the potential risk of supplementation, but also that there was still reason to breastfeed even if the infant was mixed fed or that breastfeeding for even 1 day was better than not at all. Moreover, this approach might help to reduce some of the guilt that mothers feel at not meeting breastfeeding goals. ${ }^{31}$ Infant feeding decisions are complex and affected by many wider uncontrollable circumstances and barriers. ${ }^{34}$ Mothers may have competing circumstances that reduce the likelihood of exclusive breastfeeding, but partial breastfeeding may be a good solution for them. This needs to be recognized, and presenting breastfeeding as " 1 day at a time" could help overcome this. If discussions could be more open with women, giving them the information and tools they need to make an informed choice, perhaps women may breastfeed for longer, or even initiate when they otherwise would not, just for a few days. Importantly, recognition of what they have done, rather than what they have not, may help reduce feelings of guilt at stopping breastfeeding.

A further theme was the belief that more information was needed on what breastfeeding was really like. Many mothers can encounter challenges such as pain, difficulties getting the infant latched on, or simply feeling overwhelmed by the responsibility of breastfeeding, compounded by little knowledge of how breastfeeding works. ${ }^{10-12}$ The concept of antenatal education glossing over the challenging side of breastfeeding out of fear that it might dissuade women from breastfeeding is evident in the literature. ${ }^{35,36}$ However, the early days postpartum can often feel exhausting and unrelenting as the new mother learns how to care for a dependent infant. ${ }^{37}$ Calls have been made for women to be more accurately prepared prenatally for the experience of postnatal fatigue and responsibility $^{38}$ and the realities of breastfeeding as a skill that for many develops over time. ${ }^{39}$ This is not to say that breastfeeding should be portrayed as an insurmountable obstacle, but at present mothers can be presented with idealistic images that are hard to meet in reality (as would idealistic portrayal of most behaviors). Maternal self-efficacy and confidence to breastfeed have been shown to predict breastfeeding duration. ${ }^{40}$ Giving mothers a clear insight into what issues they might face, but in addition equipping them antenatally to overcome these may increase maternal confidence that she will be able to breastfeed. Indeed, in other areas of maternal and infant health, such as childbirth, this approach is typically taken; women prepare for and develop strategies for the challenge of giving birth. Why is the same not done in a balanced way for breastfeeding? Suggesting that mothers would not choose to breastfeed if they deemed it to present even the slightest challenge seems condescending and certainly creates issues when challenges are inevitably encountered.

Finally, mothers called for breastfeeding promotion to target a wider audience, as they felt that their ability or enjoyment of breastfeeding was affected by the attitudes and knowledge of those around them. Indeed, the attitudes of those close to the mother, including the woman's partner, wider family, and peers, are shown to directly and indirectly affect a woman's decision to initiate and continue breastfeeding. ${ }^{41}$ Mothers are more likely to breastfeed for longer when their partner is positive $^{42}$ and knowledgeable ${ }^{43}$ about breastfeeding. Fathers also express desire to receive more information about breastfeeding to be able to support their partner. ${ }^{44}$

It was felt important that messages should target society as a whole, so that new mothers would feel confident in their decision to breastfeed. Although the law now protects women when breastfeeding their infants in public, attitudes toward the subject can be derogatory. Many surveys show that despite the general public typically agreeing with the breast is best message, many take umbrage with seeing a woman breastfeeding her baby. ${ }^{45}$ Mothers recognized that although new mothers are primarily responsible for breastfeeding, without a network that encourages, supports, and recognizes the importance of breastfeeding, their journey was going to be much more difficult. Our behavior, no matter how deliberate, is determined by social, economic, and environmental influences, ${ }^{46}$ and infant feeding is no different. Breastfeeding promotion has previously been criticized as placing the mother solely in control and responsible for behavior and outcomes of infant feeding, when in fact she is influenced both consciously and subconsciously by wider social, cultural, and political contexts. ${ }^{47,48}$

On the surface, it appears that the findings of this research suggest innovative and novel ways of changing the way breastfeeding promoted in the United Kingdom is needed. However, on closer inspection of policy guidelines for breastfeeding education and support, the ideas that emerged should already be in practice. The Department of Health Start 4 Life scheme already promotes many of the ideas that were discussed, such as every feed making a difference and giving details of where to find a range of support and advice. ${ }^{49}$ Similarly, the UNICEF Baby Friendly states that all pregnant women should be informed about the health benefits and management of breastfeeding, given support postnatally to establish breastfeeding and provided with specific details of where to get support if problems occur. It appears that the policy, evidence, and guidance are already in place for new mothers to be supported, but that these messages may not be getting through to new mothers, or may be drowned out by other influences such as negative attitudes from family, friends, and the public.

Although policy may be in place to support breastfeeding mothers, in reality evidence shows that although most health professionals are willing and skilled in providing such support, many have so many competing demands that they do not have the time to offer support. ${ }^{50,51}$ Others may have their own negative experiences of breastfeeding that may affect their ability or belief in delivering positive breastfeeding support. $^{52}$ The natural solution, as arose in the data, is for extensive training to be offered to those working to support new 
mothers and for wider, more accessible support services to be put in place. Interventions should go outside of simply maternal natal care, targeting fathers, family members, and society itself. The government must spread messages about the importance and normality of breastfeeding more widely, to reinforce laws protecting women to breastfeed and to remove formula advertising completely from media sources. Implementing these strategies would mean that breastfeeding becomes the normal and expected way to feed an infant and that future generations of women would feel more informed, confident, and supported in doing so.

However, in the United Kingdom, the current government has withdrawn funding of the annual Breastfeeding Awareness week, the Infant Feeding Survey, and reduced numbers of specialist infant feeding coordinators in the United Kingdom $^{53}$ with pressure continuing to grow on the midwifery work force to pick up the shortfall. ${ }^{54}$ Given the significant costs of treating illnesses in formula fed infants, ${ }^{55}$ it seems counterproductive for the government to do anything but direct more funding toward breastfeeding services. Recognition needs to be given to this.

Limitations of the work include the selective sample used. Recruitment methods mean that mothers who held strong opinions about their experiences or attitudes toward breastfeeding education and support in the United Kingdom may have been more likely to respond. However, responses were received from mothers who did not follow through their intention to breastfeed and who breastfed for varying durations. Internet recruitment may have enhanced this, with the potential to be biased toward a more affluent demographic. Internet-based recruitment is growing in popularity in health research, ${ }^{56,57}$ particularly for studies in maternal and infant health. ${ }^{58,59}$ Care should be taken in considering whether the findings are generalizable to a wider population.

Limitations aside, this article offers insight into the live experiences of mothers affected by breastfeeding policy and practice in the United Kingdom today and is of relevance to anyone working to support new mothers or to develop breastfeeding promotion, education, or policy. The key lesson that emerges is that breastfeeding needs to be repositioned as the normal way to feed a baby, with this message going to those supporting the mother and wider society. However, these messages need to be realistic about what breastfeeding is like and an understanding that every breastfeed matters needs to be portrayed. Mothers need accurate information and skilled, sensitive, and appropriate support, taking into account their wider social and cultural situation and needs.

\section{Acknowledgment}

Thanks to Dr. Magda Sachs for her comments on an earlier draft.

\section{Disclosure Statement}

No competing financial interests exist.

\section{References}

1. Horta BL, Bahl R, Martines JC, et al. Evidence on the Long-term Effects of Breastfeeding: Systematic Reviews and Meta-analyses. Geneva, Switzerland: World Health Organisation, 2007.
2. Ip S, Chung M, Raman G, et al. Breastfeeding and Maternal and Infant Health Outcomes in Developed Countries. Evidence Report/Technology Assessment Number 153; AHRQ Publication No. 07-E007. 2007. Agency for Healthcare Research and Quality U.S. Department of Health and Human.

3. DH 2013 Department of Health statistical releases on breastfeeding, smoking and obesity. Breastfeeding initiation and prevalence at 6 to 8 weeks Available at http:// webarchive.nationalarchives.gov.uk/20130402145952/http:// media.dh.gov.uk/network/261/files/2012/11/breastfeedinginitiation-and-prevalence-at-6-to-8-weeks-q3.xls\#T1_Init_ National!A1 (accessed October 30, 2015).

4. SACN. Infant Feeding Survey 2005: A commentary on Infant Feeding Practices in the UK Position Statement by the Scientific Advisory Committee on Nutrition. London: TSO, 2008.

5. Thomson G, Bilson A, Dykes F. Implementing the $\mathrm{WHO} /$ UNICEF baby friendly initiative in the community: A 'hearts and minds' approach. Midwifery 2012;28:258-264.

6. Bolling K, Grant C, Hamlyn B, et al. Infant Feeding Survey 2005. London: The Information Centre, 2007.

7. Forster DA, McLachlan HL, Rayner J, et al. The early postnatal period: Exploring women's views, expectations and experiences of care using focus groups in Victoria, Australia. BMC Pregnancy Childbirth 2008;22:27-32.

8. ONS. Key Statistics for England and Wales, March 2011. London: Office for National Statistics.

9. McAndrew F, Thompson J, Fellows L, et al. Infant Feeding Survey 2010. Leeds: Health and Social Care Information Centre, 2012.

10. Li R, Fein SB, Chen J, et al. Why mothers stop breastfeeding: Mothers' self reported reasons for stopping during the first year. Pediatrics 2008;122:69-76.

11. Brown AE, Raynor P, Lee MD. Comparison of health professionals' and mothers' perceptions of factors that influence the decision to breast or bottle feed. $J$ Adv Nurs 2011;67: 1993-2003.

12. Thulier D, Mercer J. Variables associated with breastfeeding duration. J Obstet Gynecol Neonatal Nurs 2009; 38:259-268.

13. Guyer J, Millward LJ, Berger I. Mothers' breastfeeding experiences and implications for professionals. $\mathrm{Br} \mathrm{J}$ Midwifery 2012;20:724-733.

14. Stewart-Knox BJ. Why we don't breastfeed our children and what we should do about it. Nutr Bull 2013;38:57-60.

15. Avery A, Magnus J. Expectant fathers' and mothers' perceptions of breastfeeding and formula feeding: A focus group study in three US cities. J Hum Lact 2011;27: 47-154.

16. Brown AE, Lee MD. An exploration of the attitudes and experiences of mothers in the UK who breastfeed exclusively for six months postpartum. Breastfeed Med 2012;6: 197-204.

17. McQueen KA, Dennis CL, Stremler R, et al. A pilot randomized controlled trial of a breastfeeding self-efficacy intervention with primiparous mothers. J Obstet Gynecol Neonatal Nurs 2011;40:35-46.

18. McInnes RJ, Chambers JA. Supporting breastfeeding mothers: Qualitative synthesis. J Adv Nurs 2008;62:407-427.

19. Dykes F, Flacking R. Encouraging breastfeeding: A relational perspective. Early Hum Dev 2010;86:733-736.

20. World Health Organisation. Global strategy for infant and young child feeding. Geneva, Switzerland: 55th World Health Assembly, 2003. 
21. Office for National Statistics. NS-SEC-2005. London: Palgrave Macmillan, 2005.

22. Sandelowski M. What's in a name? Qualitative description revisited. Res Nurs Health 2010;33:77-84.

23. Bernard HR. Research Methods in Anthropology. Walnut Creek, CA: AltaMira, 1995.

24. Creswell J. Qualitative Inquiry and Research Design: Choosing Among Five Traditions. Thousand Oaks, CA: Sage, 1998.

25. Guest G, Bunce A, Johnson L. How many interviews are enough? An experiment with data saturation and variability. Field Methods 2006;18:59-82.

26. Wiessinger D. Watch your language. J Hum Lact 1996;12: $1-4$.

27. WHO. Statement on breastfeeding. 2011. Available at www .who.int/mediacentre/news/statements/2011/breastfeeding 20110115/en (accessed October 30, 2015).

28. NHS. Off to the best start. 2015. Available at www.clch.nhs. uk/media/163989/start4life_off_to_the_best_start_leaflet.pdf (accessed October 30, 2015).

29. Hannan A, Li R, Benton-Davis S, et al. Regional variation in public opinion about breastfeeding in the United States. J Hum Lact 2005;21:284-288.

30. Burns E, Fenwick J, Sheehan A, et al. Mining for liquid gold: Midwifery language and practices associated with early breastfeeding support. Matern Child Nutr 2013;9:57-73.

31. Lee E. Breast-feeding advocacy, risk society and health moralism: A decade's scholarship. Sociol Compass 2011;5: 1058-1069.

32. Hill PD, Humenick SS. Insufficient milk supply. Image $J$ Nurs Sch 1989;21:145-148.

33. Quigley MA, Kelly YJ, Sacker A. Breastfeeding and hospitalization for diarrheal and respiratory infection in the United Kingdom Millennium Cohort Study. Pediatrics 2007; 119:e837-e842.

34. Racine EF, Frick KD, Strobino D, et al. How motivation influences breastfeeding duration among low-income women. J Hum Lact 2009;25:173-181.

35. Hauck Y, Irurita V. Constructing compatibility: Managing breastfeeding and weaning from the mothers perspective Qual Health Res 2003;12:897-914.

36. Williamson I, Leeming D, Lyttle S, et al. 'It should be the most natural thing in the world': Exploring first-time mothers' breastfeeding difficulties in the UK using audiovideo diaries and interviews. Matern Child Nutr 2011;8: 434-447.

37. Heinig MJ. Addressing maternal fatigue: A challenge to in-hospital breastfeeding promotion. J Hum Lact 2010;26: 231-232.

38. Troy NW. Is the significance of postpartum fatigue being overlooked in the lives of women?. MCN Am J Matern Child Nurs 2003;28:252-257.

39. Bartick M, Edwards RA, Walker M, et al. The Massachusetts baby-friendly collaborative: Lessons learned from an innovation to foster implementation of best practices. J Hum Lact 2010;26:405-411.

40. Wilhelm S, Rodehorst K, Stepans M, et al. Influence of intention and self efficacy levels on duration of breastfeeding for midwest rural mothers. Appl Nurs Res 2008; 21:123-130.

41. Andrew N, Harvey K. Infant feeding choices: Experience, self-identity and lifestyle. Matern Child Nutr 2011;7: 48-60.
42. Susin L, Giugliani E. Inclusion of fathers in an intervention to promote breastfeeding: Impact on breastfeeding rates. J Hum Lact 2008;24:386-392.

43. Rempel A, Rempel J. The breastfeeding team: The role of involved fathers in the breastfeeding family. J Hum Lact 2011;27:115-121.

44. Brown A, Davies R. Fathers' experiences of supporting breastfeeding: Challenges for breastfeeding promotion and education. Matern Child Nutr 2014;10:510-526.

45. Spuries P, Babineau J. A qualitative study of attitudes toward public breastfeeding among young Canadian Men and Women. J Hum Lact 2010;27:131-137.

46. Tones K, Tilford S. Health Promotion: Effectiveness, Efficiency and Equity. London: Nelson Thornes, 2001.

47. Dykes F. The education of health practitioners supporting breastfeeding women: Time for critical reflection. Matern Child Nutr 2006;2:204-216.

48. Kukla R. Ethics and ideology in breastfeeding advocacy campaigns. Hypatia 2006;21:157-180.

49. NHS. Start for Life. 2015. Available at www.nhs.uk/ start4life/babies (accessed October 30, 2015).

50. Collins CT, Fereday J, Pincombe J, et al. An evaluation of the satisfaction of midwives' working in midwifery group practice. Midwifery 2010;26:435-441.

51. Furber CM, Thomson AM. Midwives in the UK: An exploratory study of providing newborn feeding support for postpartum mothers in the hospital. J Midwifery Womens Health 2007;52:142-147.

52. Hauck Y, Fenwick J, Dhaliwal S, et al. The association between women's perceptions of professional support and problems experienced on breastfeeding cessation: A Western Australian study. J Hum Lact 2010;27, 49-57.

53. Boseley S. Breastfeeding week dropped by government. Guardian 2011;18:10

54. DoH. Midwifery 2020: Delivering expectations. Chief Nursing Officers of England, Northern Ireland, Scotland and Wales, 2010

55. Renfrew MJ, Pokhrel S, Quigley M, et al. Preventing disease and saving resources: The potential contribution of increasing breastfeeding rates in the UK. Report commissioned by Unicef, UK, October 2012.

56. Ferguson S, Hansen E. A preliminary examination of cognitive factors that influence interest in quitting during pregnancy. J Smoking Cessation 2012;7:100-104.

57. Hamilton K., White K.M., Cuddihy T. Using a single-item physical activity measure to describe and validate parents' physical activity patterns. Res Q Exerc Sport 2012;83:340-345.

58. Hall W, Irvine V. E-communication among mothers of infants and toddlers in a community-based cohort: Acontent analysis. $J$ Adv Nurs 2008;65:175-183.

59. Plantin L, Daneback K. Parenthood, information and support on the internet: A literature review of research on parents and professionals online. BMC Fam Pract 2009;10:34.

Address correspondence to: Amy Brown, PhD

Department of Public Health, Policy and Social Sciences Swansea University

Room 136 Haldane Building Swansea SA2 8PP

United Kingdom

E-mail: a.e.brown@swansea.ac.uk 